\title{
A INTERDISCIPLINARIDADE NO CURSO DE CIÊNCIAS CONTÁBEIS: PRÁTICAS DOCENTES NAS UNIVERSIDADES DO ESTADO DO RIO GRANDE DO NORTE
}

\section{INTERDISCIPLINARITY IN THE ACCOUNTING SCIENCES COURSE: TEACHING PRACTICES AT THE UNIVERSITIES OF THE STATE OF RIO GRANDE DO NORTE}

\section{LA INTERDISCIPLINARIDAD EN EL CURSO DE CIENCIAS CONTABLES: PRÁCTICAS DOCENTES EN LAS UNIVERSIDADES DEL ESTADO DE RÍO GRANDE DO NORTE}

\begin{abstract}
VALDÉRIO FREIRE MORAES JUNIOR
Mestre em Contabilidade pelo Programa Multiinstitucional e Inter-regional de Pós Graduação em Ciências Contábeis - UnB-UFPB-UFRN e especialista em Controladoria e Gestão de Negócios pela UFRN.

valderio@ufrnet.br

ANEIDE OLIVEIRA ARAUJO

Doutora em Controladoria e Contabilidade pela Universidade de São Paulo, professora do Programa Multiinstitucional e Inter-regional de Pós Graduação em Ciências Contábeis - UNB/UFPB/UFRN e professora do Departamento de Ciências Contábeis da Universidade Federal do Rio Grande do Norte.

aneide@ufrnet.br
\end{abstract}

\section{RESUMO}

A interdisciplinaridade se propõe a diminuir a fragmentação do ensino nas universidades, fortalecendo as competências e as habilidades nos discentes, a partir da relação entre conteúdo e disciplinas e o mercado de trabalho, apoiado em uma atitude interdisciplinar do corpo docente. A presente pesquisa tem como objetivo iden- 
tificar as práticas de interdisciplinaridade nas disciplinas específicas dos cursos de Ciências Contábeis das universidades do Rio Grande do Norte. Para tanto, foi utilizado um questionário com perguntas abertas e fechadas, preenchido por 65 docentes, representando $90 \%$ da população. A análise dos dados obtidos demonstra que a interdisciplinaridade é praticada parcialmente por meio da relação de conteúdos das disciplinas ministradas, principalmente com as antecedentes e concomitantes da atitude interdisciplinar, que se preocupa com a integração da pesquisa e a extensão ao ensino, bem como associar os conteúdos às possibilidades de aplicação no mercado de trabalho.

Palavras-chave: Ensino Superior; Fragmentação do ensino, Interdisciplinaridade; Ciências Contábeis; Práticas docentes.

\section{ABSTRACT}

Interdisciplinary approaches aim to reduce the fragmentation of teaching in universities, strengthening students' skills and abilities, by relating content, subjects and the labor market, thus supporting an interdisciplinary approach to teaching. This research seeks to identify the interdisciplinary practice of teaching courses in the specific disciplines of Accounting Science at the University of Rio Grande do Norte. For this we used a questionnaire with open and closed questions, completed by 65 teachers, representing $90 \%$ of the population. The analysis shows that interdisciplinarity is practiced in part through the relationship of the content of courses taught primarily in history, and conditions the interdisciplinary approach concerned with the integration of research and its extension to education, as well as associates the content to the possibilities for application in the labor market.

Keywords: Higher Education; Fragmentation, Interdisciplinarity, Accounting; Teaching

\section{RESUMEN}

La interdisciplinaridad se propone a disminuir la fragmentación de la enseñanza en las universidades, fortaleciendo las capacidades y las habilidades en los discentes, desde la relación entre contenido y disciplinas y el mercado de trabajo, apoyado en una actitud interdisciplinar del cuerpo docente. La presente pesquisa tiene como objetivo identificar las prácticas de interdisciplinaridad en las disciplinas específicas de los cursos de Ciencias Contables de las universidades de Río Grande do Norte. Para ello, fue utilizado un cuestionario con preguntas abiertas y cerradas, rellenado por 65 docentes, 
A Interdisciplinaridade no Curso de Ciências Contábeis: Práticas Docentes nas Universidades do Estado do Rio Grande do Norte

representando $90 \%$ de la población. El análisis de los datos logrados demuestra que la interdisciplinaridad es practicada parcialmente por medio de la relación de contenidos de las disciplinas impartidas, principalmente con las antecedentes y concomitantes de la actitud interdisciplinar, que se preocupa por la integración de la pesquisa y la extensión a la enseñanza, así como asociar los contenidos a las posibilidades de aplicación en el mercado de trabajo.

Palabras-Clave: Enseñanza Superior; Fragmentación de la enseñanza, Interdisciplinaridad; Ciencias Contables; Prácticas docentes.

\section{INTRODUÇÃO}

As discussões sobre interdisciplinaridade tiveram início na década de 60, na Europa, quando estudiosos franceses e italianos começaram a se preocupar com a crescente fragmentação do ensino. No Brasil, os primeiros estudos começaram na década de 70, sendo Japiassu (1976) o pioneiro, que afirma haver uma troca entre os especialistas e existir uma integração real das disciplinas no interior de um projeto de pesquisa.

No modelo disciplinar, segundo Santomé (1998), cada professor preocupa-se apenas com sua matéria, considerando-a sempre a mais importante e forçando os estudantes a interessar-se só por ela, podendo recorrer à desvalorização de outras que consideram rivais. Desse modelo resulta a fragmentação de ensino que ocorreu em todas as áreas, não somente na área contábil.

O Ministério da Educação (MEC), por meio do Parecer CNE/CES 776/97, emitiu uma orientação geral para as diretrizes curriculares dos cursos de graduação, incentivando uma formação sólida para que os egressos superem os desafios no exercício profissional como também na produção do conhecimento e venham a ter várias habilitações diferenciadas em um programa de curso para expandir suas grades curriculares.

O parágrafo $1 .^{\circ}$ do art. $2 .^{\circ}$ da Resolução do CNE/CES n. ${ }^{\circ} 10$, de 10/12/04, define que o projeto pedagógico, além da clara concepção do curso de graduação em Ciências Contábeis, contemple formas de realização de interdisciplinaridade. Segundo Zabala (2002, p.33), uma das principais formas de interdisciplinaridade se dá pela "transferência de leis de uma disciplina a outra, originando, em alguns casos, um novo corpo disciplinar". Trata-se de um conjunto de práticas que visam unir disciplinas com conteúdos específicos ou gerais, bem como o estreitamento entre a teoria e a prática.

Nos cursos de Ciências Contábeis, nem sempre ela é tratada de forma explícita, segundo pesquisas recentes sobre o assunto. No entanto, pode-se afirmar que existe, pelo menos, na percepção dos principais atores do processo de formação profissional, 
docentes, discentes e coordenadores de cursos. (PASSOS, 2004); (SINATORA et. al, 2005); (FRAGOSO, RIBEIRO FILHO e LIBONATI, 2006); (PADOAN e CLEMENTE, 2006); (MIRANDA e MIRANDA, 2006); (PEREIRA,2006); (ALTHOFF e DOMINGUES, 2008); (OLIVEIRA, PAIVA e MELO, 2008); (PELEIAS et al, 2008).

No entanto, nessas pesquisas não foram evidenciadas quais são as práticas da interdisciplinaridade utilizadas pelos docentes dos cursos de graduação em Ciências Contábeis, constituindo-se objetivo do presente estudo, que se espera que possa contribuir para aprimorar a prática docente na formação de profissionais da Contabilidade.

A pesquisa analisa as práticas adotadas pelos docentes no segundo semestre do ano de 2008, a partir de uma amostra representativa de $90 \%$ dos professores de disciplinas específicas da área contábil em exercício nas universidades públicas e privadas do Estado do Rio Grande do Norte que ofertam cursos de Ciências Contábeis.

Este trabalho é composto da presente introdução, na qual constam os antecedentes do problema, a justificativa, a problemática e os objetivos; da metodologia; das técnicas e dos instrumentos utilizados para a coleta e a análise de dados; do referencial teórico; dos resultados; e das considerações finais.

\section{METODOLOGIA}

Ao se utilizar o método indutivo, procurou-se investigar a quantidade de fenômenos por meio de uma observação sistemática que permitisse a identificação e a classificação, bem como a existência de relações entre variáveis, a fim de estabelecer uma generalização dessas relações e, assim, inferir uma verdade geral do que foi examinado, conforme Lakatos e Marconi (2006).

Adotou-se uma abordagem qualitativa, procurando dar ao pesquisador a oportunidade de conhecer o objeto no ambiente em que ele se insere, captando a essência e o significado do discurso das pessoas, de acordo com Bogdan e Biklen (1982) apud Lüdke e André (1986). Os dados foram coletados sem interferência do pesquisador e tratados de forma descritiva, tendo em vista identificar, relatar e comparar elementos. Segundo Raupp e Beuren (2004, p.81), "intermediário entre a pesquisa exploratória e a explicativa, caracteriza-se por não ser tão preliminar como a primeira e nem tão aprofundada como a segunda".

O ponto de partida foi a pesquisa bibliográfica, tendo como base, principalmente, livros especializados na área, artigos científicos, dissertações, sites da internet, os quais proporcionaram a construção do referencial teórico sobre a interdisciplinaridade, os conceitos afins e as suas características, bem como a definição do estado da arte a respeito do tema na área do ensino de Contabilidade, e se constituiu no alicerce essencial ao trabalho de campo e ao tratamento e à interpretação dos dados coletados. 


\section{Instrumento de coleta e tratamento dos dados}

Na coleta, foi utilizado um questionário empregando uma escala Likert com três proposições: sim, totalmente; sim, parcialmente; e não, para assim identificar o grau de utilização das práticas interdisciplinares, seguidas de uma questão aberta com vistas a identificar causas relacionadas. As questões fechadas foram tratadas de forma descritiva e as abertas por meio da análise de conteúdo, visando "a descrição objetiva, sistemática e quantitativa do conteúdo manifesto da comunicação". (BERELSON, 1971 apud BARDIN, 1977)

O objeto de estudo da análise de conteúdo é a palavra utilizada por determinados atores e em contextos específicos, enfim, o seu significado. Em termos práticos, a análise dos resultados será consequência de testes de associação de palavras - estereótipos e conotações -, de acordo com Bardin (1977), em busca de indutores úteis na análise. Os indutores funcionam como estímulo ao conteúdo das respostas, das palavras induzidas ou suscitadas que devem ser agrupadas por significado, descontando-se idênticas, sinônimas ou próximas em nível semântico, para que possam ser adequadas e objetivamente tratadas. Eles podem surgir como intuições a partir de uma leitura flutuante ou por meio de um brain-storming individual para as quais convém formular hipóteses ainda que provisórias. (BARDIN, 1977)

\section{População e amostra}

A população objeto de estudo foi constituída pelos 72 professores de disciplinas específicas dos cursos de Ciências Contábeis das universidades do Rio Grande do Norte, das quais são requeridas por essas instituições atividades de ensino, pesquisa e extensão, essenciais às práticas interdisciplinares, conforme Quadro 1.

\section{Quadro 1 - População e Amostra}

\begin{tabular}{|l|c|c|c|}
\hline Universidade & Campus & Quantidade de docentes & Amostra (respondentes) \\
\hline \multirow{2}{*}{ UFRN } & Natal & 26 & 23 \\
\cline { 2 - 4 } & Caicó & 6 & 4 \\
\hline UERN & Mossoró $\left(^{*}\right)$ & 24 & 23 \\
\hline UNP & Natal - Mossoró & 16 & 14 \\
\hline Total & $\mathbf{7 2}$ & $\mathbf{6 5}$ \\
\hline
\end{tabular}

Fonte: Coordenação de cada universidade contatada

$\left(^{*}\right)$ Os campos de Patu, Macau, Alexandria e João Câmara são atendidos pelos mesmos professores do campus de Mossoró.

Dos 72 questionários enviados obteve-se o retorno de 65, constituindo-se, assim, uma amostra possível de $90,3 \%$ da população estudada. 


\section{REFERENCIAL TEÓRICO}

\section{Fragmentação do ensino}

O conhecimento fragmentado, segundo Lück (1995), constitui-se um paradigma da complexidade do mundo atual, rompendo-se o elo da simplicidade e produzindo um homem despreparado para enfrentar os problemas globais, por exigir uma formação não apenas polivalente, porém voltada à realidade em uma atitude de aprendizagem contínua.

De acordo com Santos (2007), a fragmentação do saber educacional, por ser decorrente da fragmentação histórica do ser, do saber e do mundo, tem repercussões principalmente no saber e no fazer pedagógico. Dessa maneira, esse fenômeno produz efeitos na dinâmica interna da organização escolar, como também de forma epistemológica. Contudo, a academia apenas reflete a chamada cisão epistemológica, que é captada de maneira gradativa na mente humana já fragmentária.

Conforme Garcia (2006), as escolas têm investido na formação de docentes e a interdisciplinaridade atualmente faz parte do vocabulário desses profissionais. Portanto, os professores já poderiam estar mais preparados perante a existência da fragmentação. Por isso, ainda pairam muitas questões para que se chegue à superação dessa dificuldade.

Segundo Morin (2002, p. 491), uma aparente complexidade de integração de conceitos de várias disciplinas pode ser superada pelo exercício de interação e retroação, sem busca de "homogeneidade que sacrifique a visão de coisas particulares e concretas". Os conhecimentos, quando organizados, favorecem um entendimento integral, contribuindo para um agrupamento das partes a partir de um elo natural, ligando pontos considerados distantes e diferentes a fim de conhecer o todo. O professor que não amplia seus saberes além dos limites da sua disciplina tende a se especializar e utilizar como regra principal o ensino fragmentado. (MORIN, 2002)

Santos (2007) entende que uma atitude ontológica e interdisciplinar e, por conseguinte, dialética pode pressupor como cada disciplina deve ser tratada, compondo o currículo escolar como uma trajetória desenvolvida pelo aluno em relação à totalidade concreta para não ser considerada um fragmento fechado. Nesse sentido, enxerga na interdisciplinaridade a viabilização de um trabalho sério a ser inserido na educação como base de apoio a todas as disciplinas, para que cada matéria não passe a ser vista de forma hermética.

\section{Interdisciplinaridade}

De acordo com os Parâmetros Curriculares Nacionais (PCN), a proposta curricular que contemple o desenvolvimento de competências essenciais ao bom desempenho profissional tem sua organização pedagógica em torno de três princípios orientadores: a contextualização, a interdisciplinaridade e as habilidades. (BRASIL, 2002) 
A Interdisciplinaridade no Curso de Ciências Contábeis: Práticas Docentes nas Universidades do Estado do Rio Grande do Norte

Essa interdisciplinaridade não se restringe à associação temática, mas à articulação entre ensino, pesquisa e trabalho, sem perda de conteúdos e a partir de ações coordenadas e orientadas para objetivos bem definidos. Já Araújo (2008) aponta como um dos obstáculos na estrutura curricular atual a chamada disciplinarização do conhecimento, que impede a percepção da maneira como as disciplinas se relacionam e as suas conexões de uma forma geral.

Para Lück (1995, p. 64), esse processo envolve:

A integração e engajamento de educadores num trabalho conjunto, de interação das disciplinas do currículo escolar entre si e com a realidade, de modo a superar a fragmentação do ensino, objetivando a formação integral dos alunos.

Dessa forma, os discentes podem exercer criticamente a cidadania, perante uma visão global de mundo, como também ter capacidade de enfrentar complexos problemas, amplos e globais da realidade atual.

\section{Formas de interdisciplinaridade}

Segundo Pereira (2006), a interdisciplinaridade é apresentada de três maneiras: formas de relacionamento entre as disciplinas, atitude interdisciplinar e pesquisa interdisciplinar. As formas de relacionamento mostram como as disciplinas podem estar interligadas para enriquecer o conhecimento dos indivíduos; já a atitude interdisciplinar está voltada a uma postura do docente, aberta a mudanças no ensino; e, por último, a pesquisa interdisciplinar, que é uma superação da fragmentação do ensino aproximando a teoria da prática.

Então, a tarefa interdisciplinar é executada com atitude e método para que se possa ter uma integração de conteúdos, saindo de uma concepção fragmentária para aquela que seja unitária do conhecimento, para que supere a dicotomia entre ensino e pesquisa, de forma que o processo de ensino-aprendizagem seja permanente. (PEREIRA, 2006)

Segundo Lück (1995), disciplinas vistas como convergentes podem, muitas vezes, juntas, resolver um problema comum quando há a relação da ação e o ato da decisão, por meio da articulação entre conteúdos, da complementaridade e da integração de áreas diferentes.

O relacionamento entre as disciplinas pode ocorrer por meio de uma classificação dos tipos de interdisciplinaridade, conforme discorre Carlos (2008): Interdisciplinaridade heterogênea: é uma espécie de enciclopedismo, baseada na soma de informações procedentes de disciplinas diversas, tendo como tipo de enfoque o caráter enciclopédico; Pseudointerdisciplinaridade: é quando existe uma estrutura de união, geralmente um modelo teórico ou um marco conceitual, no sentido de trabalhar em disciplinas que são muito 
diferentes entre si, utilizando-se de instrumentos de análise que seriam o denominador comum das pesquisas; Interdisciplinaridade auxiliar: é mais durável, pois ocorre quando uma disciplina toma de empréstimo métodos ou procedimentos de uma outra, o que geralmente acontece por uma ocasionalidade ou situações provisórias; Interdisciplinaridade compósita: é a necessidade imperiosa em encontrar soluções técnicas quando se trata de resolver grandes e complexos problemas gerados pela sociedade atual, como guerra, fome, delinquência, poluição, entre outros; Interdisciplinaridade unificadora: é uma coerência estreita entre os domínios de estudo das disciplinas, podendo haver uma integração teórica e dos métodos correspondentes, sendo um ponto atingido por meio de pesquisa científica.

Várias são as formas, portanto, de se tratar interdisciplinaridade, cabendo ao corpo docente decidir que caminho seguir ao verificar problemas escolares vividos nas instituições e a experiência pedagógica de cada professor.

\section{Práticas interdisciplinares na docência}

A interdisciplinaridade sozinha não pode solucionar os problemas educacionais, porém ela contribui para amenizar essa situação a partir de uma atitude que favoreça a mudança na postura pedagógica que procure incentivar a pesquisa, estimulando a iniciativa, a cooperação e a co-responsabilidade entre as disciplinas. (VAIDEANU, 1987)

Para tanto, uma atitude que seja interdisciplinar evidencia, primeiro, um projeto que venha a ser aprovado e agregado ao currículo, por meio de uma proposta que supere uma visão fragmentada de ensino, tornando o conhecimento como fonte de uma visão global do mundo. Segundo Fazenda (2007b, p. 13), essa atitude implica reciprocidade, diálogo entre pares, humildade diante da limitação do próprio saber, perplexidade ao desvendar novos saberes, desafio perante o novo e redimensionamento do velho, envolvimento, comprometimento e responsabilidade. Há, portanto, uma dose de ousadia e doação pessoal ao se adotar uma atitude interdisciplinar que se concretiza, segundo Carlos (2008), por meio de um processo que vai além do plano epistemológico, teórico, metodológico e didático, gerando a possibilidade do encontro, da partilha, da cooperação e do diálogo. Isso sugere uma ação conjunta dos professores.

\section{Interdisciplinaridade nos cursos de Ciências Contábeis}

O professor de Contabilidade tem focado a transmissão dos conhecimentos ao dar importância ao tecnicismo associado aos conteúdos mecanicistas, formando o profissional dentro dos padrões da racionalidade técnica. Porém, o docente dessa área precisa ser um profissional rico em saberes, capaz de intervir no momento devido e trabalhar com práticas pedagógicas com caráter inovador, permitindo a apropriação do seu trabalho, através da reflexão de suas ações. (LAFFIN, 2005) 


\section{repec}

A Interdisciplinaridade no Curso de Ciências Contábeis: Práticas Docentes nas Universidades do Estado do Rio Grande do Norte

Na sua gênese, o ensino superior de Contabilidade, iniciado no Brasil em 1945, teve como foco o conhecimento técnico voltado para escrituração dos livros contábeis. Anos depois, o profissional dessa área tornou-se necessário, a partir da expansão do mercado de capitais no Brasil, com a obrigatoriedade das demonstrações financeiras e do parecer de um auditor independente possuidor do título de Bacharel em Ciências Contábeis. (PASSOS, 2004)

No ano de 1968, a reforma do ensino universitário trouxe para esse ambiente a departamentalização e a matrícula por disciplina. Nos cursos de Ciências Contábeis, ela ocorreu por meio da Resolução n. ${ }^{\circ}$ 03/92 do Conselho Federal de Educação, por intermédio da criação do currículo mínimo, exaltando uma qualificação melhor aos profissionais da área, com a inclusão de disciplinas como Monografia e Trabalho de Conclusão de Curso.

As competências e as habilidades definidas pelas Diretrizes Curriculares Nacionais no Curso de Graduação em Ciências Contábeis, de 16 de dezembro de 2004, do Conselho Nacional de Educação/Câmara de Educação Superior (CNE/CES), de acordo com o artigo $4 .^{\circ}$, inciso II, afirmam que o curso deve demonstrar visão sistêmica e interdisciplinar da atividade contábil para fortalecer seus discentes.

Dessa maneira, observa-se um posicionamento claro por parte da legislação educacional quando incentiva a interdisciplinaridade tanto no ensino quanto na pesquisa contábil, pois os currículos estão sendo adequados às necessidades do mercado, buscando dos profissionais um conhecimento amplo nas diversas áreas de domínio.

Estudos sobre interdisciplinaridade nos cursos de Ciências Contábeis têm evidenciado a preocupação da comunidade acadêmica contábil para a questão, no entanto, ainda não aponta soluções para sua prática efetiva.

Passos (2004), por exemplo, considerou-o um assunto complexo, com visões divergentes entre os autores e, à época, ausente dos estudos realizados na pós-graduação stricto sensu da área contábil. Sinatora et. al (2005), ao analisarem as condições de oferta dos conteúdos de Sistemas de Informação nos cursos de Ciências Contábeis na cidade de São Paulo, identificaram a existência de pouca integração entre os docentes. Fragoso, Ribeiro Filho e Libonati (2006), no entanto, verificaram que a prática interdisciplinar tende a ser intensificada nos níveis de maior titulação.

Padoan e Clemente (2006) observaram que a disciplinaridade cruzada é praticada no contexto de disciplinas específicas do curso, não contemplando as chamadas acessórias, como economia e sociologia. Por sua vez, Miranda e Miranda (2006) constataram alguns pontos de interdisciplinaridade, principalmente no final do curso, pois, a partir daí, cresce o número de disciplinas aplicáveis e mais relacionadas.

Pereira (2006) verificou que diversas Instituições de Ensino Superior (IES) praticam a multidisciplinaridade, com áreas do conhecimento distintas do campo da Contabilidade, 


\section{repec}

proporcionando alguma forma de relacionamento, a partir da participação em grupos de pesquisa nas diversas áreas do conhecimento. Segundo ela, a existência de um corpo docente oriundo de diversas áreas propicia a instauração de uma atitude interdisciplinar, no entanto, esta não se constitui um elemento relevante na formação que facilite a inserção no mercado de trabalho, na opinião dos egressos.

Oliveira, Paiva e Melo (2008) evidenciaram a percepção dos discentes a respeito da prática interdisciplinar, ainda que de forma tímida, e a sua contribuição para a formação e o desenvolvimento de competências profissionais por meio de uma pesquisa realizada em uma IES privada do Estado de Minas Gerais.

Peleias et al (2008) concluíram que, no ensino da disciplina Controladoria de quatro IES da cidade de São Paulo, a interdisciplinaridade não está inserida de maneira ampla e clara, entretanto sua relevância é percebida entre os atores da prática docente.

\section{ANÁLISE DOS RESULTADOS}

\section{Caracterização da amostra}

A amostra representativa de $90 \%$ dos professores de disciplinas específicas dos cursos de Ciências Contábeis ofertados pelas universidades do Estado do Rio Grande do Norte em 2008 está composta por 65 respondentes - 34,39\% do sexo feminino e $65,61 \%$ do sexo masculino. Desses, $78,5 \%$ atuam em IES pública e $21,5 \%$ em IES privada.

A maior parte $(49,4 \%)$ tem como titulação máxima a especialização, seguidos de mestres $(30,76 \%)$, graduados $(18,46 \%)$ e doutores $(1,54 \%)$, atuantes nas áreas financeira $(34,14 \%)$, gerencial $(45,12 \%)$ e auditoria e perícia $(26,15 \%)$, havendo casos de participação em mais de uma área.

A maioria também está composta por profissionais experientes, considerando que $49,24 \%$ atuam no magistério superior há mais de 5 anos; $15,38 \%$ possuem entre 4 e 5 anos de experiência; e o restante $(35,38 \%)$ tem menos de 3 anos de experiência.

\section{Práticas de interdisciplinaridade}

Indagados a respeito de como relacionam os conteúdos da disciplina com o ambiente social e o mercado de trabalho, $62 \%$ dos docentes afirmaram estabelecer uma relação total, enquanto $38 \%$ disseram que o fazem parcialmente. Essa relação se dá a partir de exemplos, resultados de pesquisas divulgadas em revistas científicas ou anais de eventos, relato de situações reais, reportagens e entrevistas publicadas no noticiário ou em revistas especializadas, sob a forma de exemplos práticos $(36,92 \%)$ e estudos de casos $(24,61 \%)$; $13,85 \%$ incluíram o mercado; $12,31 \%$ teceram comentários sobre a prática; e 12,31\% citaram outros pontos, conforme Tabela 3. 
Tabela 3 - Formas de relacionamento da teoria com a prática

\begin{tabular}{c|c|c}
\hline Significado & Frequência & $\%$ \\
\hline Exemplos de livros & 24 & 36,92 \\
\hline Mercado de trabalho & 17 & 26,16 \\
\hline Estudos de caso & 16 & 13,85 \\
\hline Outros pontos & 8 & 12,31 \\
\hline Total & 65 & 100,00 \\
\hline
\end{tabular}

Fonte: Elaborado pelo autor (2009)

Outros pontos apresentados pelos docentes, com frequência de 12,31\%, foram: atualização por meio de sites, revistas e jornais; levantamento de questões do dia-a-dia dos profissionais da área; notícias da atualidade; aula com uma realidade econômica e financeira; artigos publicados; fatos empíricos com a teoria exposta; realidade local com visitas às empresas; potencial da região para a técnica; e explicação das prerrogativas da profissão.

As respostas indicam que existe atitude interdisciplinar na medida em que os professores não restringem o processo de ensino ao texto didático, mas recorrem a outras informações que extrapolam o espaço da sala de aula.

Considerando o perfil dos respondentes, observa-se que a maior parte dos especialistas da área financeira tende a usar mais os exemplos, enquanto a maioria dos mestres da área gerencial explora estudos de casos. Já o mercado de trabalho é mais citado pelos mestres e especialistas com mais experiência na docência e pertencentes à área financeira. Por sua vez, a prática contábil é frisada mais pelos especialistas da área financeira e com pouco tempo de experiência.

\section{Incentivo à realização de pesquisa}

Pode-se constatar que $40 \%$ afirmaram incluir a pesquisa de forma significativa no período da disciplina; $43 \%$ disseram fazer parcialmente; e $17 \%$ responderam que não fazem pesquisa na graduação, havendo quem afirmasse que a graduação não é "lugar para pesquisa, mas, sim, para formar profissionais". Quanto à forma, observou-se que esse incentivo se dá $33,85 \%$ pela leitura e/ou pela confecção de artigos na disciplina; $26,15 \%$ fazem pesquisa de campo; $23,07 \%$ passam trabalhos e $16,93 \%$ não os fazem, conforme Tabela 4 abaixo:

Tabela 4 - Formas de incentivo à pesquisa

\begin{tabular}{l|c|c}
\hline Significado & Frequência & $\%$ \\
\hline Elaboração de artigos & 22 & 33,85 \\
\hline Pesquisa de campo & 17 & 26,15 \\
\hline Trabalhos & 15 & 23,07 \\
\hline Não fazem & 11 & 16,93 \\
\hline Total & 65 & 100 \\
\hline
\end{tabular}

Fonte: Elaborado pelo autor (2009) 
Considerando o perfil dos respondentes, constata-se que: mulheres, mestres e especialistas adotam mais artigos. A pesquisa de campo é requerida tanto pelos mestres quanto pelos especialistas das áreas financeira, gerencial e auditoria/perícia. Os docentes que não fazem pesquisa são, na sua maioria, os graduados com pouco tempo na docência.

\section{Criação de situações-problema}

Dos 65 respondentes, 55\% afirmaram criar totalmente situações-problema baseadas em casos reais para fortalecer a aprendizagem dos novos conhecimentos; $42 \%$ disseram que o fazem parcialmente; e 3\% responderam que não. Aqueles que o fazem utilizam com recurso $38,46 \%$ por meio de casos; $27,69 \%$ relato de situações reais, $10,78 \%$ exemplos; e $20,00 \%$ citaram outros pontos, conforme Tabela 5 abaixo:

Tabela 5 - Formas de criação de situação-problema

\begin{tabular}{l|c|c}
\hline Significado & Frequência & $\%$ \\
\hline Casos & 25 & 38,46 \\
\hline Situações reais & 18 & 27,69 \\
\hline Exercícios & 7 & 10,78 \\
\hline Outros pontos & 13 & 20,00 \\
\hline Não faz & 2 & 3,07 \\
\hline Total & 65 & 100 \\
\hline
\end{tabular}

Fonte: Elaborado pelo autor (2009)

Considerando o perfil dos respondentes: os especialistas e os mestres mais experientes da área gerencial trabalham com casos. Já os especialistas do campo financeiro, com menos tempo na docência, utilizam-se de situações reais, enquanto os docentes graduados, no início da carreira, de áreas distintas - financeira e gerencial - se apoiam em trabalho de campo e seminários.

\section{Vinculação da disciplina ministrada com outras do curso}

Constata-se que $31 \%$ vinculam a disciplina com outras matérias antecedentes que estão sendo ministradas; $26 \%$ disseram fazer a vinculação concomitante e $12 \%$ com disciplinas futuras; $5 \%$ optaram por responder que o vínculo ocorre entre antecedentes e concomitantes; $6 \%$ citaram antecedentes e futuras; e, por sua, vez $20 \%$ acreditam que as disciplinas estão interligadas de uma maneira universal, ou seja: passado, presente e futuro. O sentido da vinculação da disciplina ministrada é apresentado na Tabela 6. 
Tabela 6 - Vinculação da disciplina com outras do curso

\begin{tabular}{l|c}
\hline Sentido da vinculação & $\%$ \\
\hline Antecedentes & 31 \\
\hline Concomitante & 26 \\
\hline Futuras & 12 \\
\hline Antecedentes e concomitantes & 6 \\
\hline Antecedentes, concomitantes e futuras & 20 \\
\hline Total & 100 \\
\hline
\end{tabular}

Fonte: Elaborado pelo autor (2009)

Quanto à forma de estabelecimento dessa vinculação, 33,85\% dos professores citaram suas experiências já vivenciadas ao longo do período de sala de aula. Já 27,69 apenas enfatizaram que fazem vinculação, conforme Tabela 6 .

Tabela 6 - Termos citados pelos docentes na questão n. ${ }^{\circ} 4$

\begin{tabular}{l|c|c}
\hline Significado & Frequência & $\%$ \\
\hline Citação & 22 & 33,85 \\
\hline Vinculação & 18 & 27,69 \\
\hline Conhecimentos & 17 & 26,15 \\
\hline Base & 5 & 7,69 \\
\hline Interdisciplinaridade & 3 & 4,62 \\
\hline Total & 65 & 100 \\
\hline
\end{tabular}

Fonte: Elaborado pelo autor (2009)

Para estabelecer uma relação entre o perfil dos respondentes, observa-se que os mestres e os especialistas mais experientes das três áreas -gerencial, financeira e auditoria/perícia - corroboram com a mesma opinião, ou seja, que a vivência faz com que o professor integre sua disciplina com outras do curso. Já "vinculação" foi o termo citado pelos mestres e o doutor do campo gerencial com mais experiência. Por sua vez, conhecimentos e base serviram de alicerce para o comentário dos especialistas da área gerencial não tão experientes. Por último, três professores citaram o termo interdisciplinaridade: dois especialistas e um mestre.

\section{Relação entre atividade de extensão e a disciplina ministrada}

Dos 65 respondentes, $17 \%$ fazem essa relação total de atividades de extensão - seminários, fórum, congresso, entre outros -; $54 \%$ afirmaram que realizam parcialmente; $29 \%$ optaram em responder que nenhuma atividade de extensão é vinculada à disciplina ministrada. 
Indagados sobre a forma, observou-se que $33,85 \%$ incentivam os alunos a participarem de eventos; $23,08 \%$ realizam atividades e/ou trabalhos; $13,85 \%$ realizam seminários; e 29,22\% não relacionam atividade de extensão no período da disciplina, conforme Tabela 7.

Tabela 7 - Termos citados pelos docentes na questão $\mathrm{n}^{\circ} \mathbf{5}$

\begin{tabular}{l|c|c}
\hline Significado & Frequência & $\%$ \\
\hline Participação em eventos & 22 & 33,85 \\
\hline Atividades e/ou trabalhos & 18 & 23,08 \\
\hline Seminários & 9 & 13,85 \\
\hline Não relacionam & 19 & 29,22 \\
\hline Total & 65 & 100 \\
\hline
\end{tabular}

Fonte: Elaborado pelo autor (2009)

Confrontado com o perfil dos respondentes, observa-se que os mestres e o doutor (com mais de quatro anos de experiência) afirmaram incentivar os alunos para participar de eventos que porventura venham a ocorrer. Já a maioria dos mestres e dos especialistas da área gerencial, que possuem entre 1 a 3 anos de experiência, estimulam a elaboração, por parte dos discentes, de trabalhos relacionados à atividade de extensão ocorrida. A participação nos seminários é realizada principalmente por especialistas da área de auditoria com pouca experiência. Por sua vez, os professores menos experientes, com titulação tanto de graduado quanto de especialista das três áreas - gerencial, financeira e auditoria/perícia - não relacionam atividade de extensão com a disciplina ministrada.

\section{Avaliação de trabalho integrada com outros docentes}

Observou-se que, da amostra analisada, 26,15\% afirmaram existir totalmente a possibilidade de avaliar em conjunto com outros professores com práticas interdisciplinares; $38,85 \%$ disseram fazer essa avaliação parcialmente, ou seja, com possibilidades de realização, enquanto $35 \%$ disseram não existir essa prática.

Tabela 8 - Termos citados pelos docentes na questão n. $^{\circ} 6$

\begin{tabular}{l|c|c}
\hline Significado & Frequência & $\%$ \\
\hline Práticas interdisciplinares & 17 & 26,15 \\
\hline Sem possibilidades de realização & 25 & 35,00 \\
\hline Com possibilidades de realização & 23 & 38,85 \\
\hline Total & 65 & 100 \\
\hline
\end{tabular}

Fonte: Elaborado pelo autor (2009) 


\section{repec}

A Interdisciplinaridade no Curso de Ciências Contábeis: Práticas Docentes nas Universidades do Estado do Rio Grande do Norte

As respostas fornecidas corroboram para constatar a existência de práticas interdisciplinares realizadas pelos docentes em $26,15 \%$ das respostas. Os professores acabam conversando com outros professores para analisar o conteúdo e vincular os trabalhos realizados, como também frisaram a utilidade de haver planejamento e regras bem estabelecidas, para que possam existir trabalhos em grupo como uma forma de integração disciplinar.

Por intermédio da interdisciplinaridade, os docentes afirmaram conseguir avaliar trabalhos integrados no mesmo semestre, principalmente com as disciplinas que têm pontos em comum. Daí, conforme o respondente 4, "utiliza-se dos conhecimentos adquiridos em outras disciplinas para enriquecer a que estou ministrando".

Alguns docentes $(35 \%)$ responderam sem possibilidades de realização. Devido à estrutura curricular e de infra-estrutura, não permitem a aplicação integrada. Já outros professores $(38,85 \%)$ frisaram com possibilidades de realização a avaliação integrada, porém ainda não conseguiram realizá-la.

O respondente 56 afirma tratar-se de uma possibilidade, porém exige a realização de um trabalho de equipe, definindo como funciona a integração. Para tanto, no momento da confecção do plano de ensino, deve ser observada essa realidade, evitando-se, inclusive, que os alunos façam uma reclamação costumeira em sala de aula, quando observam ter visto alguns conteúdos em disciplinas ministradas anteriormente. Daí, o docente supracitado diz ser possível o entrelaçamento entre as matérias, não de forma repetitiva, mas fortalecendo principalmente as mais afins, como é o caso de análise de balanços e gerencial, por exemplo.

Confrontado com o perfil dos respondentes, observa-se que na maioria os mestres da área gerencial mais experientes revelaram suas práticas sobre a integração dos trabalhos integrados com outros professores. Já os professores do campo gerencial e financeiro, incluindo o doutor e os especialistas, com uma relativa experiência, afirmaram não ter ainda feito, mas que existe a possibilidade de realização. Por sua vez, os graduados e os especialistas menos experientes foram mais taxativos e disseram não haver chance de concretizar esse tipo de integração.

\section{CONSIDERAÇÕES FINAIS}

Este trabalho tem como objetivo principal evidenciar a práticas de interdisciplinaridade nos cursos de Ciências Contábeis oferecidos pelas Universidades do Rio Grande do Norte. Considerando o que preconiza a literatura, existem três formas de praticar a interdisciplinaridade: o relacionamento entre os conteúdos das disciplinas, a atitude interdisciplinar do docente e a pesquisa interdisciplinar. Essas formas se sustentam nos pilares do ensino universitário: ensino, pesquisa e extensão. 
Observou-se que a atitude interdisciplinar está presente nas ações de professores com maior titulação e experiência profissional. Porém, quanto ao relacionamento e de conteúdos entre as disciplinas, tem-se mais ênfase na utilização de referências a disciplinas antecedentes e concomitantes, mas não se usa sistematicamente a pesquisa e a extensão para colocar o estudante em situações de uso dos conteúdos relacionados.

Do mesmo modo, atividades conjuntas de avaliação, embora sejam reconhecidas por alguns como possíveis, deixam de ser realizadas em virtude da estrutura curricular, bem como de aspectos estruturais. Espera-se com esses achados contribuir para orientar a introdução de práticas interdisciplinares mais efetivas, influenciando a ampliação de atitude docente e estimulando a realização de pesquisa com essa conotação. Além disso, espera-se suscitar novos estudos que contemplem abordagens experimentais para que se possa conhecer a eficácia de adoção dessas práticas no processo de aprendizagem.

\section{REFERÊNCIAS}

ALTHOFF, Noemia Schroeder; DOMINGUES, Maria José Carvalho de Souza. Práticas interdisciplinares nos cursos de graduação em Ciências Contábeis: mito ou realidade. In: CONGRESSO DAASSOCIAÇÃO NACIONAL DOS PROGRAMAS DE PÓS-GRADUAÇÃO EM CONTABILIDADE, 2, 2008, Salvador. Anais... Salvador: ANPCONT, p. 1-16, 2008.

ARAÚJO, Maria Inês Oliveira. A dimensão ambiental no currículo: construindo a esperança. In: ARAÚJO, Maria Inês Oliveira; OLIVEIRA, Luiz Eduardo (Orgs). Desafios da formação de professores para o século XXI: o que deve ser ensinado? O que deve ser aprendido. Aracaju: Editora UFS, 2008.

BARDIN, Laurence. Análise de conteúdo. Lisboa: Edições 70, Lda, 1977.

BRASIL. PCN + Ensino Médio: orientações educacionais complementares aos Parâmetros Curriculares Nacionais. Ciências humanas e suas tecnologias. Brasília: Ministério da Educação, 2002.

CARLOS, Jairo Gonçalves. Interdisciplinaridade: o que é isso? Disponível em: <www. unb.br/ppgec/dissertacoes/proposicoes/proposicao_jairocarlos.pdf>. Acesso em: 04 de outubro de 2008.

CONSELHO FEDERAL DE EDUCAÇÃO. RESOLUÇÃO N. 3, DE 5 DE OUTUBRO DE 1992. Fixa os mínimos de Conteúdos e duração do curso de graduação em Ciências Contábeis. Disponível em: <www.jusbrasil.com.br>. Acesso em: 20 de fevereiro de 2008. 
CONSELHO NACIONAL DE EDUCAÇÃO - CÂMARA DE EDUCAÇÃO SUPERIOR - PARECER CNE/CES 776, DE 03 DE DEZEMBRO DE 1997. Orientação para as diretrizes curriculares dos cursos de graduação. Disponível em: <www.mec.gov.br>. Acesso em: 18 de janeiro de 2008.

CONSELHO NACIONAL DE EDUCAÇÃO - CÂMARA DE EDUCAÇÃO SUPERIOR - RESOLUÇÃO CNE/CES 10, DE 16 DE DEZEMBRO DE 2004. Diretrizes Curriculares Nacionais para o Curso de Graduação em Ciências Contábeis, bacharelado. Disponível em: $<$ www.mec.gov.br>. Acesso em: 18 de janeiro de 2008.

FAZENDA, Ivani Catarina Arantes. Interdisciplinaridade: história, teoria e pesquisa. 14. ed. Campinas: Papirus, 2007b.

FRAGOSO, Adriana Rodrigues; RIBEIRO FILHO, José Francisco; LIBONATI, Jerônymo José. Um estudo aplicado sobre o impacto da interdisciplinaridade no processo de pesquisa dos doutores em contabilidade no Brasil. Revista Universo Contábil, Blumenau, v. 2, n. 1, p. 103-112, jan./abr. 2006.

GARCIA, Joe. As práticas invisíveis da interdisciplinaridade. In: FAZENDA, Ivani. (Org.) Interdisciplinaridade na formação de professores: da teoria à prática. Canoas: ULBRA, 2006.

JAPIASSU, Hilton. Interdisciplinaridade e patologia do saber. Rio de Janeiro: Imago, 1976.

LAFFIN, Marcos. De contador a professor: a trajetória da docência no ensino superior da contabilidade. Florianópolis: Imprensa Universitária, 2005.

LAKATOS, Eva Maria; MARCONI, Marina de Andrade. Técnicas de pesquisa: planejamento e execução de pesquisas, amostragens e técnicas de pesquisa, elaboração, análise e interpretação de dados. 6. ed. São Paulo: Atlas, 2006.

LÜCK, Heloísa. Pedagogia interdisciplinar. Fundamentos teórico-metodológicos. Petrópolis: Vozes, 1995.

LUDKE, Menga; ANDRÉ, Marli E. D. Pesquisa em Educação: Abordagens qualitativas. São Paulo : EPU, 1986. 
MIRANDA, Cláudio; MIRANDA, Raissa Álvares de Matos. Interdisciplinaridade e métodos de ensino no curso de contabilidade: um estudo no Nordeste Paulista. In: CONGRESSO USP DE CONTROLADORIA E CONTABILIDADE, 6, 2006, São Paulo. Anais... São Paulo: USP, v. 6, p. 1-15, 2006.

MORIN, Edgar. A religação dos saberes: o desafio do século XXI: idealizadas e dirigidas por Edgar Morin. 2. ed. Rio de Janeiro: Bertrand Brasil, 2002.

OLIVEIRA, Michelle Cristina de Souza Mendes; PAIVA, Kelly César Martins; MELO, Marlene Catarina de Oliveira Lopes. Formação de Competências Profissionais e Interdisciplinaridade no Curso de Ciências Contábeis: percepções dos discentes. In: ENCONTRO DA ANPAD, 32, 2008, Rio de Janeiro. Anais... Rio de Janeiro: ANPAD, v. 1. p. 1-16, 2008.

PADOAN, Fátima Aparecida da Cruz; CLEMENTE, Ademir. A interdisciplinaridade no ensino da Contabilidade: um estudo empírico da percepção dos docentes. In: CONGRESSO USP DE CONTROLADORIA E CONTABILIDADE, 6, 2006, São Paulo. Anais... São Paulo: USP, v. 6, p. 1-15, 2006.

PASSOS, Ivan Carlin. A interdisciplinaridade no ensino e na pesquisa contábil: um estudo no município de São Paulo. 2004. 164f. Dissertação (Mestrado em Ciências Contábeis) - Faculdade de Economia, Administração e Contabilidade. Universidade de São Paulo, São Paulo, 2004.

PELEIAS, Ivam Ricardo et al. Pesquisa sobre a percepção da interdisciplinaridade por professores de Controladoria em cursos de Ciências Contábeis na cidade de São Paulo. In: ENCONTRO DA ANPAD, 32, 2008, Rio de Janeiro. Anais... Rio de Janeiro, ANPAD, v. 1. p. 1-15, 2008.

PEREIRA, Ivone Vieira. Interdisciplinaridade no Ensino: a percepção dos egressos dos cursos de graduação em Ciências Contábeis. 2006. 123f. Dissertação (Mestrado em Ciências Contábeis). Universidade de Brasília, Brasília, 2006.

RAUPP, Fabiano Maury; BEUREN, Ilse Maria. Metodologia da pesquisa aplicável às Ciências Sociais. In: BEUREN, Ilse Maria (Org). Como elaborar trabalhos monográficos em contabilidade: teoria e prática. 2. ed. São Paulo: Atlas, 2004.

SANTOMÉ, Jurjo Torres. Globalização e interdisciplinaridade: o currículo integrado. Porto Alegre: Artes Médicas, 1998. 
SANTOS, Vivaldo Paulo dos. Interdisciplinaridade na sala de aula. São Paulo: Loyola, 2007.

SINATORA, José Roberto Pereira et al. Construção e validação de uma escala de atitude para a avaliação do ensino de Sistemas de Informação nos cursos de Ciências Contábeis da cidade de São Paulo. In: ENCONTRO NACIONAL DOS PROGRAMAS DE PÓS-GRADUAÇÃO EM ADMINISTRAÇÃO, 29, Brasília. Anais... Rio de Janeiro: ANPAD, p. 1-15, 2005.

VAIDEANU, George. Interdisciplinarity in education: a tentative synthesis. In: Quartely review of education. United States, v. 17, p. 489-501, 1987.

ZABALA, Antoni. Enfoque globalizador e pensamento complexo: uma proposta para o currículo escolar. Porto Alegre: Artmed, 2002. 